\title{
Central Composite Design as a Tools for Optimization of Antioxidant Activity on Cocoa Shell Extract
}

\author{
Arief Huzaimi Md Yusof, Siti Salwa Abd Gani, Uswatun Hasanah Zaidan, Mohd Izuan Effendi \\ Halmi
}

\begin{abstract}
This study seeks to analyze and optimize the antioxidant activity thru beta carotene bleaching assay influenced by different extraction condition on extracts obtained from Malaysia Cocoa Shell. The condition was optimized by response surface methodology with five levels of the model. There are three variables involved in this study, namely: ethanol concentration (70-90 v/v \%), temperature $\left(45-65^{\circ} \mathrm{C}\right)$, and ultrasound irradiation time (30-60 min). The optimum condition obtains for temperature, duration of extraction and solvent concentration were $55{ }^{\circ} \mathrm{C}, 45$ minutes and $63.18 \%$ respectively at a constant frequency of 40 $\mathrm{kHz}$. In this condition, the antioxidant activity experimental was $98.91 \pm 0.5 \%$ and predicted $98.44 \%$. The ANOVA shows the coefficient of determination $\left(R^{2}\right)$ and the lack of fit test was 0.9846 and 0.6105 respectively. The desirability function from T-test data, modeled equation fits the data, reveals that the design can be used to predicting future observation within the design range.
\end{abstract}

Index Terms: antioxidant, cocoa shells and response surface methodology.

\section{INTRODUCTION}

In recent years, an antioxidant present in the fruits and vegetables play an important role in neutralized or eliminate free radical by donating one of its electrons. The benefit of antioxidant usually received from good dietary. The previous study shows that the antioxidant can give a benefit to human health such as antioxidant compound was used as an anti-inflammatory, reduce cardiovascular disease, anti-cancer, anti-wrinkles and anti-aging [1]. There many ways to measure the capacity of antioxidant from plant extract such as thru antioxidant assay (scavenging activity assay, reduction antioxidant power assay, bleaching assay, total antioxidant assay, and radical trapping assay)[2].

Beta-carotene bleaching assay (BCB) was one of the

Revised Manuscript Received on September 22, 2019.

Arief Huzaimi Md Yusof, Malaysia Cocoa Board, Cocoa Innovative and Technology Centre, Lot 12621 Nilai Industrial Area, 71800 Nilai, Negeri Sembilan, Malaysia, Halal Products Research Institute, Universiti Putra Malaysia, Putra Infoport, 43400 Serdang, Selangor, Malaysia.

Siti Salwa Abd Gani, Halal Products Research Institute, Universiti Putra Malaysia, Putra Infoport, 43400 Serdang, Selangor, Malaysia, Department of Agriculture Technology, Faculty of Agriculture, Universiti Putra Malaysia, 43400 Serdang, Selangor, Malaysia.

Uswatun Hasanah Zaidan, Department of Biochemistry, Faculty of Biotechnology and Biomolecular Sciences, Universiti Putra Malaysia, 43400 Serdang, Selangor, Malaysia.

Mohd Izuan Effendi Halmi, Department of Land Management, Faculty of Agriculture, Universiti Putra Malaysia, Universiti Putra Malaysia, 43400 Serdang, Selangor, Malaysia. methods used to measure the capacity of antioxidant potential of non-polar antioxidants thru lipid oxidation. The lipid oxidation occurs when the oxygen species react with the lipid and perform a complex reaction chain. The previous study shows that lipid oxidation products are involved in the formation of mutagenic DNA [3], [4]. Some study reveals dietary antioxidants can protect low-density lipoprotein from oxidation and reduce the risk of atherosclerosis and cancer [5].

Cocoa shell is one of the underutilized waste beside cocoa pod husk from the cocoa industry. The previous study shows that this waste contains bioactive compound know as polyphenols [6]. Polyphenols are widely distributed in plants and are a bioactive compound that has more than one hydroxyl. There are many types of polyphenols such as flavonoids, tannins, phenolic acid, etc. This antioxidant compound plays an important role in eliminating the unstable compound such as free radicals[7]. These free radicals are dangerous to the body in either the long or the short term and can lead to certain types of diseases as mention before.

In this study, the extract from Malaysian cocoa shell (MCSE) was evaluated by BCB assay and optimized its condition of the extract by using central composite design.

\section{Methodology}

\section{A. Material and chemicals}

Cocoa shell was collected from Pusat Penyelidikan dan Pembangunan Koko (PPPK), Jengka, Pahang, Malaysia. The cocoa shell was washed clean and ground using a mechanical grinder (IKA, Staufen Germany) with $1 \mathrm{~mm}$ blade size to fine particles. Other chemicals used in the study were butylated hydroxytoluene acid (BHT), $\beta$-Carotene, linoleic acid, tween 20 and chloroform. All chemicals were of analytical grades.

\section{B. Ultrasound-assisted extraction}

One gram of cocoa shell powder was weighed and mixed with $50 \mathrm{~mL}$ ethanol (in various concentrations) in a conical flask and extracted using a sonication bath (Wiseclean, 289 W, Wongju-si, Korea) at $40 \mathrm{kHz}$ frequency, various temperatures, and durations. All experiments conditions are shown in Table I. Malaysian Cocoa shell extract (MSCE) was filtered, removed solvent and water content by using rotary evaporator (IKA, Staufen, Germany) and freeze-drying (Labconco, Kansas City, MO, USA) to get the crude extract. The dried extract was stored at $-40^{\circ} \mathrm{C}$ in sample bottles for further analysis. 


\section{Response surface methodology design (RSM)}

The central composite design (CCD) was used for investigating the influence of three independent variables on antioxidant activity by using $\beta$-Carotene. Three variables (ethanol concentrations $(\%), \mathrm{X} 1$; temperatures $\left({ }^{\circ} \mathrm{C}\right), \mathrm{X} 2$, and ultrasound irradiation time (Min), X3, were selected as parameters that should be optimized for the extraction. The three factors with five levels of the condition are shown in Table I. The alpha value was set at 1.6217 and actual level for alpha was calculated by the software. All experiment data obtained were compared with the data calculated from the second polynomial equation as in Equation 1. The complex interactions between variables were evaluated using analysis of variance (ANOVA) to determine the value of constant (Equation 1), the coefficient of determination (R2), lack of fit, and the significance of model on antioxidants of extract. All data were analyzed using Expert Design Software (version 10, Stat-Ease Inc., Minneapolis, MN, USA).

$$
Y=\beta_{0}+\sum_{i=0}^{3} \beta_{i} X_{i}+\sum_{i=0}^{3} \beta_{i i} X_{i i}^{2}+\sum_{i \neq j=0}^{3} \beta_{i j} X_{i} X_{j}
$$

\section{Determination of beta-carotene bleaching (BCB) of cocoa shell extract.}

The antioxidant activity of MSCE was evaluate using Azizah Othman et al. (2007) [8]. $0.2 \mathrm{mg} \beta$-Carotene were diluted in the $1 \mathrm{~mL}$ of chloroform. The dilution was then mixed with $0.02 \mathrm{ml}$ linoleic acid and $0.2 \mathrm{~mL}$ Tween 20 . The chloroform was removed by using rotary evaporator (IKA, Staufen, Germany). Next $50 \mathrm{~mL}$ of distilled water was added to the mixture and vortex by using () to form an emulsion. 0.2 $\mathrm{mL}$ of MSCE or standard were pipetted into a test tube containing

$2 \mathrm{~mL}$ of emulsion. The test tube was then placed in a water bath at $50{ }^{\circ} \mathrm{C}$. The absorbance was read at $470 \mathrm{~nm}$ using UV-Visible Spectrophotometer (Cary 60, Agilent

Technologies, Santa Clara, CA, USA) after 2 hours.

Degradation rate (DR) was calculated according to the first order kinetics, using equation 2.

$$
D R_{\text {Sample or standard }}=\ln \frac{a}{b} \times \frac{1}{t}
$$

Where $\ln$ is a natural $\log , a$ is the initial absorbance (470 $\mathrm{nm}$ ) at time $0, b$ is the same absorbance at 2 hours and $t$ is the initial absorbance at time 0 .

Antioxidant activity (AA) was expressed as a percent of inhibition relative to the control, using equation 3 :

$$
A A=\left(\frac{D R_{\text {control }}-D R_{\text {sample or standard }}}{D R_{\text {control }}}\right) \times 100
$$

\begin{tabular}{|c|c|c|c|c|c|c|c|c|}
\hline \multirow[b]{2}{*}{ Run } & \multicolumn{3}{|c|}{ Actual Level } & \multicolumn{3}{|c|}{ Coded Level } & \multirow[b]{2}{*}{$\begin{array}{c}\text { BCB } \\
\text { Experiment } \\
(\%)\end{array}$} & \multirow[b]{2}{*}{$\begin{array}{c}\text { BCB } \\
\text { Predict } \\
(\%)\end{array}$} \\
\hline & $\begin{array}{c}\text { Ethanol } \\
\text { Concentration } \\
\mathbf{X}_{1}(\%)\end{array}$ & $\begin{array}{c}\text { Temperature } \\
\mathrm{X}_{2}\left({ }^{\circ} \mathrm{C}\right)\end{array}$ & $\begin{array}{c}\text { Ultrasound } \\
\text { Irradiation } \\
\text { Time } \\
\mathbf{X}_{3}(\text { minutes }) \\
\end{array}$ & $\begin{array}{c}\text { Ethanol } \\
\text { Concentration } \\
\mathbf{X}_{1}(\%)\end{array}$ & $\begin{array}{c}\text { Temperature } \\
\mathrm{X}_{2}\left({ }^{\circ} \mathrm{C}\right)\end{array}$ & $\begin{array}{c}\text { Ultrasound } \\
\text { Irradiation } \\
\text { Time } \\
\mathbf{X}_{\mathbf{3}} \text { (minutes) } \\
\end{array}$ & & \\
\hline 1 & 70.00 & 45.00 & 60.00 & -1.00 & -1.00 & 1.00 & $80.63 \pm 3.5$ & 80.71 \\
\hline 2 & 70.00 & 65.00 & 60.00 & -1.00 & 1.00 & 1.00 & $93.73 \pm 11.1$ & 94.82 \\
\hline 3 & 80.00 & 38.18 & 45.00 & 0.00 & -1.62 & 0.00 & $63.08 \pm 0.7$ & 65.55 \\
\hline 5 & 70.00 & 65.00 & 30.00 & -1.00 & 1.00 & -1.00 & $93.62 \pm 1.1$ & 93.89 \\
\hline 6 & 90.00 & 65.00 & 30.00 & 1.00 & 1.00 & -1.00 & $66.89 \pm 1.1$ & 65.69 \\
\hline 7 & 80.00 & 55.00 & 45.00 & 0.00 & 0.00 & 0.00 & $66.06 \pm 2.7$ & 69.72 \\
\hline 8 & 80.00 & 55.00 & 45.00 & 0.00 & 0.00 & 0.00 & $70.08 \pm 1.6$ & 69.72 \\
\hline 9 & 80.00 & 55.00 & 70.23 & 0.00 & 0.00 & 1.62 & $66.07 \pm 0.6$ & 65.40 \\
\hline 14 & 80.00 & 55.00 & 45.00 & 0.00 & 0.00 & 0.00 & $71.41 \pm 4.9$ & 69.72 \\
\hline 15 & 90.00 & 65.00 & 60.00 & 1.00 & 1.00 & 1.00 & $58.15 \pm 11.3$ & 58.58 \\
\hline 16 & 80.00 & 55.00 & 45.00 & 0.00 & 0.00 & 0.00 & $70.18 \pm 0.9$ & 69.72 \\
\hline 17 & 70.00 & 45.00 & 30.00 & -1.00 & -1.00 & -1.00 & $86.37 \pm 4.1$ & 84.25 \\
\hline 18 & 80.00 & 55.00 & 45.00 & 0.00 & 0.00 & 0.00 & $67.29 \pm 0.2$ & 69.72 \\
\hline 19 & 80.00 & 55.00 & 45.00 & 0.00 & 0.00 & 0.00 & $73.61 \pm 9.5$ & 69.72 \\
\hline 20 & 63.18 & 55.00 & 45.00 & -1.62 & 0.00 & 0.00 & $98.91 \pm 0.5$ & 98.44 \\
\hline
\end{tabular}

Table I: Central composite design of three variables with their observed responses

\section{E. Ramp function and T-test}

Equation 1 obtained for the antioxidant activity on MSCE was tested by using a ramp function as shown in Table II to simultaneously optimize the condition and test its effectiveness with desirability function. The desirability number lies between 1 and 0 . It represents the nearest value of response to its ideal value. The values obtained from the study were then analyzed by using T-test to find its p-value by software Minitab (Version14, Minitab, Pennsylvania, USA). 


\section{F. Statistical analysis}

Statistical analysis was evaluated by analysis of variance from (ANOVA) on Expert Design software and the data obtained the ramp function were analyzed by using T-test on Minitab Software. All data collected were expressed as a mean \pm standard error.

Table II: Analysis of variance for the fitted quadratic model of BCB from Malaysia cocoa shell extract.

\begin{tabular}{cccccc}
\hline Source & Sum of Squares & $\begin{array}{c}\text { Degree of } \\
\text { freedom }\end{array}$ & Mean square & F-value & P-value \\
\hline Model & 4242.40 & 9 & 471.38 & 70.85 & $<0.0001$ \\
$\mathrm{X}_{1}$ & 3565.00 & 1 & 3565.0 & 535.84 & $<0.0001$ \\
$\mathrm{X}_{2}$ & 465.84 & 1 & 465.84 & 70.02 & $<0.0001$ \\
$\mathrm{X}_{3}$ & 107.33 & 1 & 107.33 & 16.13 & 0.0025 \\
\hline $\mathrm{X}_{1}^{2}$ & 4.29 & 1 & 4.29 & 0.64 & 0.4407 \\
$\mathrm{X}_{2}^{2}$ & 57.40 & 1 & 57.40 & 8.63 & 0.0149 \\
$\mathrm{X}_{3}^{2}$ & 0.28 & 1 & 0.28 & 0.042 & 0.8415 \\
\hline $\mathrm{X}_{1} \mathrm{X}_{2}$ & 0.018 & 1 & 0.018 & $2.719 \mathrm{E}-003$ & 0.9594 \\
$\mathrm{X}_{1} \mathrm{X}_{3}$ & 32.30 & 1 & 32.30 & 4.85 & 0.0522 \\
$\mathrm{X}_{2} \mathrm{X}_{3}$ & 12.68 & 1 & 12.68 & 1.91 & -1975 \\
\hline Residual & 66.53 & 10 & 6.65 & - & 0.6105 \\
Lack of fit & 28.90 & 5 & 5.78 & 0.77 & - \\
Pure error & 37.64 & 5 & 7.53 & - & \\
\hline $\mathrm{R}^{2}=0.9846$ & & & & & \\
$\mathrm{R}_{\text {pred }}: 0.9364$ & & & & & \\
$\mathrm{CV}_{0}=3.60$ & & & & & \\
\hline
\end{tabular}

\section{ReSUlt AND DisCUSSION.}

\section{A. Fitting the model}

The fitting of the model was determined from insignificant lack of fit test and p-value of the model. All data collected from the treatments were evaluated using ANOVA as shown in Table III. The model was significant $(\rho<0.001)$ and lack of fit test showed non-significant at $\rho>0.6105$. The coefficient of determination $\left(\mathrm{R}^{2}\right)$ of the data was 0.9846 . This show that the data most likely can be repeated with a closeness of the response with the ideal value as describe by Hakan and Sermet (2013) [9]. The complex interaction was to evaluate the constant value as in equation 4.

$$
\begin{aligned}
& Y_{B C B}=246.45560-1.91197 X_{1}-2.02710 X_{2}+ \\
& 0.36727 X_{3}+0.00047597 X_{1} X_{2}-0.013395 X_{1} X_{3}+ \\
& 0.00839338 X_{2} X_{3}+0.00545566 X_{1}^{2}+0.019958 X_{2}^{2}+ \\
& 0.000619766 X_{3}^{2}
\end{aligned}
$$

Table III: T-test on response surface methodology model and condition for ramp function on beta-carotene bleaching activity.

\begin{tabular}{ccccccccc}
\hline $\begin{array}{c}\text { Ramp } \\
\text { function }\end{array}$ & $\begin{array}{c}\text { Ethanol } \\
\text { concentration } \\
(\%)\end{array}$ & $\begin{array}{c}\text { Temperature } \\
\left.\mathbf{(}^{\mathbf{0}} \mathbf{C}\right)\end{array}$ & $\begin{array}{c}\text { Ultrasound } \\
\text { irradiation } \\
\text { time }\end{array}$ & Experiment & Prediction & S & T-value & P-value \\
\hline 1 & 81.42 & 48.99 & 19.77 & $71.58 \pm 0.076$ & 71.51 & 0.0439 & 1.60 & 0.252 \\
2 & 86.29 & 61.8 & 19.77 & $69.61 \pm 0.878$ & 70.47 & 0.5071 & -1.79 & 0.231 \\
3 & 89.09 & 61.7 & 69.43 & $54.55 \pm 0.488$ & 54.53 & 0.2829 & 0.11 & 0.925
\end{tabular}

\section{B. Response surface analysis of BCB}

All of the data were presented in Figures 1- 3. The graph shows that the interaction between the two variables was almost similar. The $\rho$-value of the linear interaction show significant with $\rho<0.005$. This data represents the parameter set to give a significant effect on the antioxidant activity. In the other hand, on the two way and quadratic interaction between variables, only ethanol concentration interact with ultrasound irradiation time and quadratic temperature gave a significant effect with $\rho<0.05$ respectively.

From the present study, the ethanol concentration increase along with the antioxidant activity either it interact with the temperature or ultrasound irradiation time. The increase in antioxidant activity due to the solvent used in the extraction. The previous study shows that there were a significant in antioxidant activity by using extraction from water and organic solvent [10]. A study was done by Javier et al (2016) on effect different solvent on anthocyanin and phenolic compounds of Renealmia Alpinia (Rottb.) mass peel show that solvent mixture compost with high methanol gave higher phenolic extract compare to anthocyanin [11]. While methanol content without other organic solvent gave higher anthocyanin and antioxidant compound [11]. This show that polarity of the extraction medium plays an important role in extraction yield for the targeted bioactive compound. Another study was done by Maja Dent et al (2013) on effect extraction solvent on the composition and mass fraction of polyphenols in Dalmatia wild sage (Salvia officinalis L.) extract show a similar result even though the composition 


\section{Central Composite Design as a Tools for Optimization of Antioxidant Activity on Cocoa Shell Extract}

solvent use in both studies are different [12]

Moreover, the optimizer of the solvent in extraction was affecting by the condition set for temperature and irradiation time. From Fig. 1 and Fig. 2 show that interaction between solvent and temperature yielded higher antioxidant activity compare to solvent and ultrasound irradiation time. In a biochemical reaction, the high temperature can decrease the solubility of the compound. According to Hassan et al. (2019) mention that, solubility values can be decreased with the decreasing of solvent polarity and increase of van der waals interaction [13]. The different polarity of the solvent interacts with the different thermal condition will give a different mixture of bioactive compound extract. In agreement with Thanh et al. (2017) found that the extraction solvent plays an important role in the extraction of targeted compound groups [14].

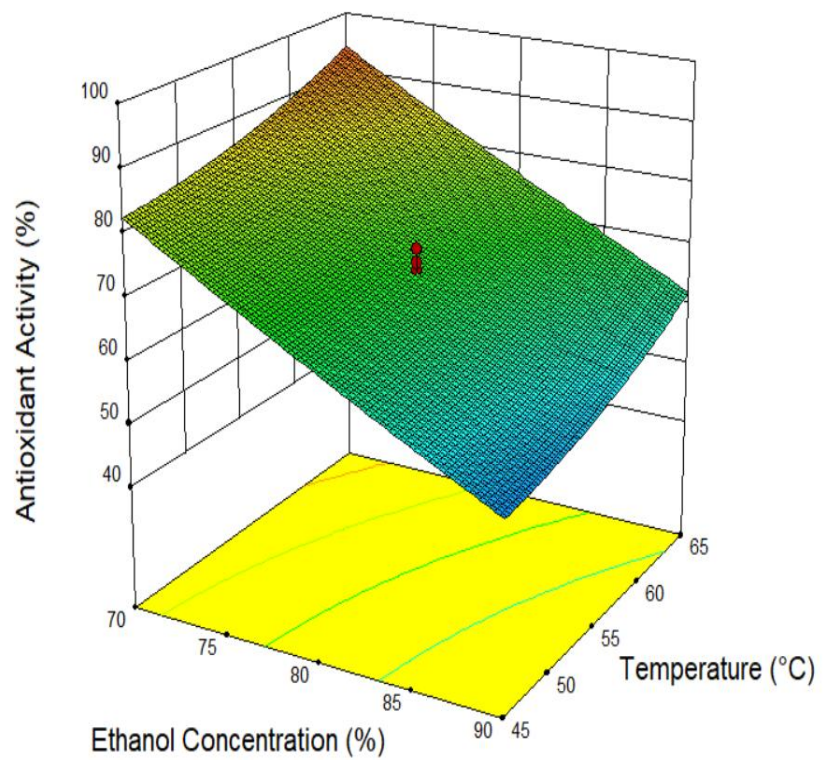

Fig. 1. Response surface plot showing the effect of extraction condition of ethanol concentration, and temperature on $\mathrm{BCB}$ of MSCE

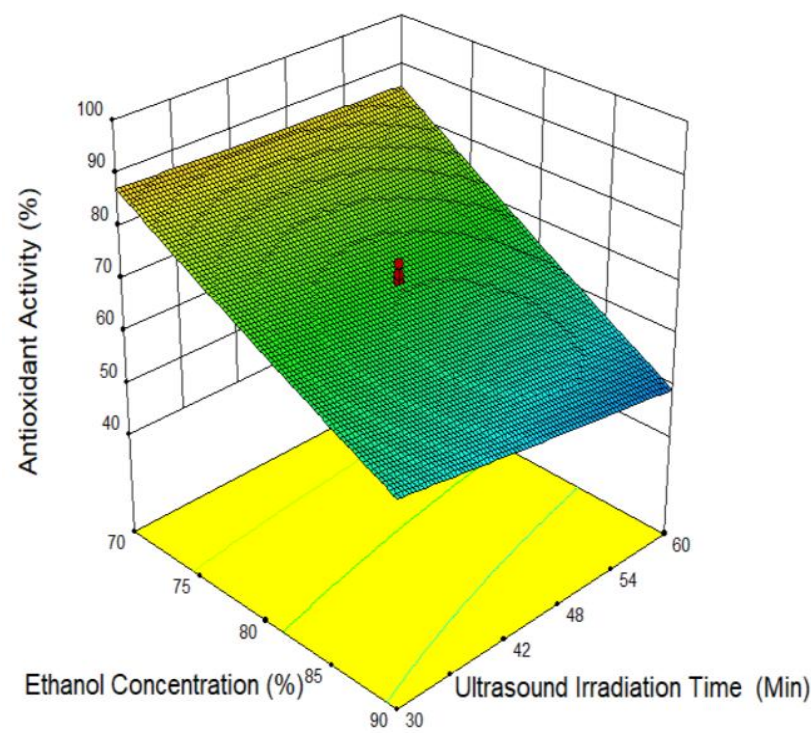

Fig. 2. Response surface plot showing the effect of extraction condition of ethanol concentration, and ultrasound irradiation time on BCB of MSCE

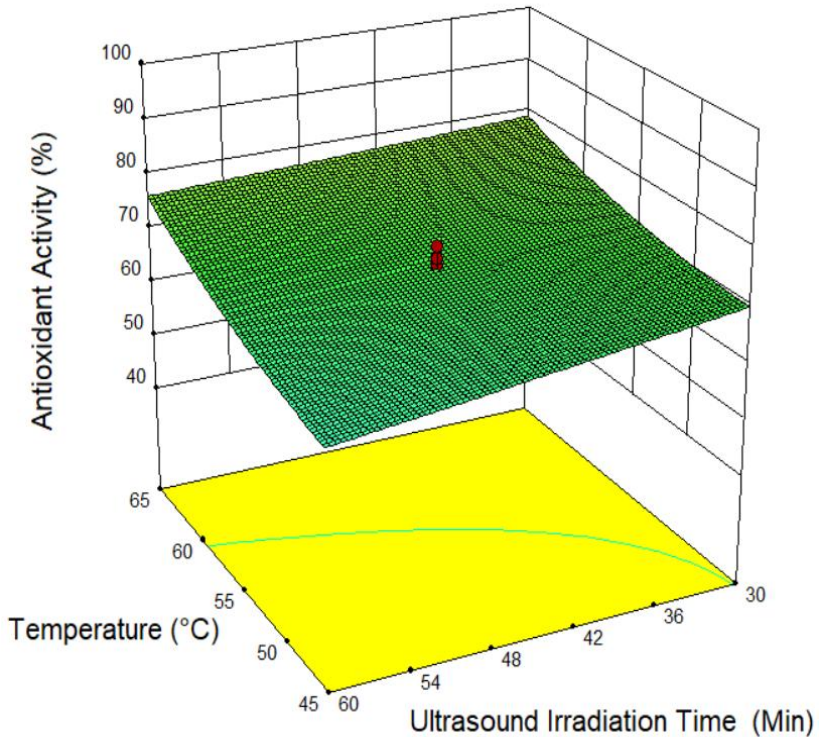

Fig. 3. Response surface plot showing the effect of extraction condition of temperature, and ultrasound irradiation time on BCB of MSCE

Besides that, the high temperature can reduce the thermal resistant of a targeted cell in natural material. In a study by Azahar. (2017) show that the range of targeted compound groups such as flavonoid and phenolic were between $60^{\circ} \mathrm{C}$ to $80{ }^{\circ} \mathrm{C}$ [15]. This in agreement with Guangyan et al. (2012) found the same range to extract the bioactive compound from natural material [16].

Although the data showed the duration and temperature gave insignificant effect to the extraction yield, the level condition set for both variables should change to see either the different condition can be optimized. The previous study showed that ultrasound irradiation time can be optimized at duration less than 35 minutes and the compound can be degraded at longer treatment as describe by Lui et al (2013) [17]. A study by Leonardo et al (2018) analyzes that the different yield in an antioxidant compound can be influenced by many factors such as the method of treatment, type of solvent use, temperature, pressure, natural material and method of analyzing [18].

\section{Verification of the model}

This study aimed to verify the model obtained from the experiment can be used with the different condition set through ram function, desirability function and analyzed the data obtained through T-test. The desirability 1 was used in this experiment as it shows the function value near 1 is most likely gave a response to its ideal value [19]. From table III, three best conditions were chosen out of a hundred conditions suggested by the software. Three conditions with high ethanol concentration (above 80\%), two levels of temperature and duration with the low and high value obtained from the model. The condition can be changed through the software for further study of the model. From the data obtained show that the experimental and predicted value is comparable and not significant in a $\rho$-value with $p>0.05$. Therefore the polynomial equation build can be used to predict future observation within the design range. 


\section{Conclusion}

Three variables, ethanol concentration, temperature, and ultrasound irradiation time was chosen to evaluate their complex interaction by using RSM for the antioxidant activity from MSCE. The effect of cocoa shell extract on antioxidant power was successfully optimized at condition, the ethanol concentration of $63.18 \%$, temperature $55{ }^{\circ} \mathrm{C}$, ultrasound irradiation time 45 minutes. From the experiment, the results show that the model and lack of fit test was significant with $\mathrm{p}<0.0001$ and non-significance $(\mathrm{p}>0.05)$ respectively. The equation built from the model can be repeated within the design range as it successfully determined from the T-test. Under these optimized conditions, the experimental antioxidant activity is $98.91 \pm 0.5$ $\%$, and the predicted value is $98.44 \%$. The study suggests the extraction of the cocoa shell was successfully optimized and can be predicted for future observation within the design range

\section{ACKNOWLEDGMENT}

This work was supported by the Malaysia Cocoa Board, Halal Product Research Institute, and Universiti Putra Malaysia (UPM).

\section{REFERENCES}

1. R. Sarangarajan, S. Meera, R. Rukkumani, P. Sankar, G. Anuradha, Antioxidants: Friend or foe?, Asian Pac. J. Trop. Med. vol. 10 (2017) 1111-1116. doi:10.1016/j.apjtm.2017.10.017, 2017.

2. S.S. Kankara, M. Mustafa, H.M. Ibrahim, R. Nulit, Effect of Drying Methods, Solid-Solvent Ratio, Extraction Time and Extraction Temperature on Phenolic Antioxidants and Antioxidant Activity of Guiera senegalensis J.F. Gmel (Combretaceae) Leaves Water Extract, Am. J. Phytomedicine Clin. Ther. vol. 2 (2014) 1378-1392, 2014.

3. A. Yadav, R. Kumari, A. Yadav, J.P. Mishra, S. Srivatva, S. Prabha, Antioxidants and its functions in human body - A Review Antioxidants and its functions in human body - A Review, Res. Environ. Life Sci. vol. 9 (2016) 1328-1331, 2016

4. S. Reuter, S.C. Gupta, M.M. Chaturvedi, B.B. Aggarwal, Oxidative stress, inflammation, and cancer: How are they linked?, Free Radic. Biol. Med. $\quad$ vol. 49 (2010) 1603-1616. doi:10.1016/j.freeradbiomed.2010.09.006.Oxidative, 2010.

5. A. Phaniendra, D.B. Jestadi, L. Periyasamy, Free Radicals: Properties, Sources, Targets, and Their Implication in Various Diseases, Indian J. Clin. Biochem. vol. 30 (2015) 11-26. doi:10.1007/s12291-014-0446-0, 2015.

6. A. Abdul Karim, A. Azlan, A. Ismail, P. Hashim, S.S. Abd Gani, B.H. Zainudin, N.A. Abdullah, Phenolic composition, antioxidant, anti-wrinkles and tyrosinase inhibitory activities of cocoa pod extract, BMC Complement. Altern. Med. vol. 14 (2014) 1-13. doi:10.1186/1472-6882-14-381, 2014.

7. M.J. Mitchell, M.R. King, Polyphenols and aging, Curr Aging Sci. vol. 3 (2014) 1-23. doi:10.1088/1367-2630/15/1/015008.Fluid, 2014

8. A. Othman, A. Ismail, N. Abdul Ghani, I. Adenan, Antioxidant capacity and phenolic content of cocoa beans, Food Chem. vol. 100 (2007) 1523-1530. doi:10.1016/j.foodchem.2005.12.021, 2007.

9. H. Akcay, A.S. Anagun, Multi response optimization application on a manufacturing factory, Math. Comput. Appl. 18 (2013) 531-538, 2013.

10. A. Thouri, H. Chahdoura, A. El Arem, A.O. Hichri, R. Ben Hassin, L. Achour, Effect of solvents extraction on phytochemical components and biological activities of Tunisian date seeds ( var . Korkobbi and Arechti), BMC Complement. Altern. Med. vol. 17 (2017) 248 doi:10.1186/s12906-017-1751-y, 2017.

11. A. Javier David Vega, R.-E. Hector, L.-G. Juan Jose, L.-G. Maria L, H.-C. Paola, Á.-S. Raúl, O.-V. Carlos Enrique, Effect of solvents and extraction methods on total anthocyanins, phenolic compounds and antioxidant capacity of Renealmia alpinia (Rottb.) Maas peel, Czech $J$. Food Sci. 2017 (2017). doi:10.17221/316/2016-CJFS, 2017.

12. M. Dent, V. Dragovi-Uzelac, M. Peni, M. Brncic, T. Bosiljkov, B. Levaj, The Effect of Extraction Solvents, Temperature and Time on the Composition and Mass Fraction of Polyphenols in Dalmatian Wild Sage
(Salvia officinalis L.) Extracts, J. Diabetes Metab. Disord. vol. 51 (2013) 84-91. doi:10.1186/2251-6581-13-11, 2013.

13. S. Hassan, F. Adam, M.R.A. Bakar, S.K.A. Mudalip, Evaluation of solvents ' effect on solubility, intermolecular interaction energies and habit of ascorbic acid crystals, J. Saudi Chem. Soc. vol. 23 (2019) 239-248. doi:10.1016/j.jscs.2018.07.002, 2019.

14. T. Van Ngo, C.J. Scarlett, M.C. Bowyer, P.D. Ngo, Q. Van Vuong, Impact of Different Extraction Solvents on Bioactive Compounds and Antioxidant Capacity from the Root of Salacia chinensis L ., J. Food Qual. (2017) 8, 2017.

15. N.F. Azahar, S. Salwa, A. Gani, N. Fadzillah, M. Mokhtar, Optimization of phenolics and flavonoids extraction conditions of Curcuma Zedoaria leaves using response surface methodology, Chem. Cent. J. (2017) 1-10. doi:10.1186/s13065-017-0324-y, 2017.

16. G. Pan, G. Yu, C. Zhu, J. Qiao, Ultrasonics Sonochemistry Optimization of ultrasound-assisted extraction ( UAE ) of flavonoids compounds ( FC ) from hawthorn seed ( HS ), Ultrason. - Sonochemistry. vol. 19 (2012) 486-490. doi:10.1016/j.ultsonch.2011.11.006, 2012.

17. G.-Y. Zhong, P. Yang, Y.-W. Liu, Applications of ultrasound in food and bioprocessing, Ultrason. Sonochem. vol. 11 (2017) 312-332. doi:10.1016/j.ejmech.2017.07.034, 2017.

18. L. Schneider, A. Ginane, B. Jr, W. Moreira, T. Siqueira, W. Herwig, A. Siuiti, Photophysical properties of $\mathrm{fl}$ avonoids extracted from Syngonanthus nitens, the golden grass, J. Lumin. vol. 194 (2018) 394-400. doi:10.1016/j.jlumin.2017.10.040, 2018.

19. R.L. Lorza, C.B. Labari, P.J.R. Fuente, Using the Multi-Response Method with Desirability Functions to Optimize the Zinc Electroplating of Steel Screws, Metal. vol. 8 (2018) 711. doi:10.3390/met8090711, 2018 .

\section{Authors Profile}

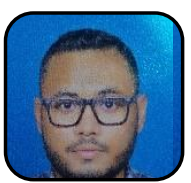

Arief Huzaimi Md Yusof Reseach Officer at Cocoa Innovative and Technology Centre, Malaysian Cocoa Board (MCB). Student (Ph.d) at Halal Products Research Institute (HPRI), Universiti Putra Malaysia (UPM). Email: ariefhuzaimi@koko.gov.my

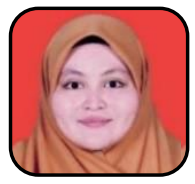

Dr. Siti Salwa Abd Gani, Associate Professor at Department of Agriculture Technology, Faculty of Agriculture, Universiti Putra Malaysia (UPM). She also a researcher at Halal Products Research Institute (HPRI), Universiti Putra Malaysia (UPM). Email ssalwaag@upm.edu.my.

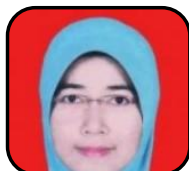

Dr. Uswatun Hasanah Zaidan, Department of Biochemistry, Faculty of Biotechnology and Biomolecular Sciences, Universiti Putra Malaysia (UPM). Email: uswatun@upm.edu.my.

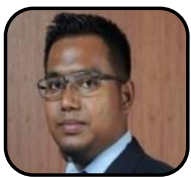

Dr. Izuan Effendi Halmi, Department of Land Management, Faculty of Agriculture, Universiti Putra Malaysia (UPM). Email: m_izuaneffendi@upm.edu.my 